\title{
BMJ Open Body composition: population epidemiology and concordance in Australian children aged 11-12 years and their parents
}

\author{
Susan A Clifford, ${ }^{\odot 1,2}$ Alanna N Gillespie,, ${ }^{\ominus 1,2}$ Timothy Olds, ${ }^{\odot 1,3}$ Anneke C Grobler, ${ }^{\odot 1}$ \\ Melissa Wake $1,2,4$
}

To cite: Clifford SA, Gillespie AN, Olds T, et al. Body composition: population epidemiology and concordance in Australian children aged $11-12$ years and their parents. BMJ Open 2019;9:95-105. doi:10.1136/ bmjopen-2018-023698

- Prepublication history and additional material for this paper are available online. To view these files, please visit the journal online (http://dx.doi. org/10.1136/bmjopen-2018023698).

Received 19 April 2018 Revised 22 October 2018 Accepted 4 April 2019

Check for updates

(c) Author(s) (or their employer(s)) 2019. Re-use permitted under CC BY-NC. No commercial re-use. See rights and permissions. Published by BMJ.

${ }^{1}$ Murdoch Children's Research Institute, Parkville, Victoria, Australia

${ }^{2}$ Department of Paediatrics, The University of Melbourne, Parkville, Victoria, Australia ${ }^{3}$ Alliance for Research in Exercise, Nutrition and Activity (ARENA), University of South Australia, Adelaide, South Australia, Australia

${ }^{4}$ Department of Paediatrics and The Liggins Institute, The University of Auckland, Auckland, New Zealand

Correspondence to Professor Melissa Wake; melissa.wake@mcri.edu.au

\section{ABSTRACT}

Objectives Overweight and obesity remain at historically high levels, cluster within families and are established risk factors for multiple diseases. We describe the epidemiology and cross-generational concordance of body composition among Australian children aged 11-12 years and their parents.

Design The population-based cross-sectional Child Health CheckPoint study, nested within the Longitudinal Study of Australian Children (LSAC).

Setting Assessment centres in seven major Australian cities and eight regional cities, or home visits; February 2015-March 2016.

Participants Of all participating CheckPoint families ( $n=1874$ ), body composition data were available for 1872 children (49\% girls) and 1852 parents (mean age 43.7 years; $88 \%$ mothers), including 1830 biological parentchild pairs.

Measures Height, weight, body mass index (BMI), waist circumference and waist-to-height ratio for all participants; body fat and fat-free mass by four-limb bioimpedence analysis (BIA) at assessment centres, or body fat percentage by two-limb BIA at home visits. Analysis: parent-child concordance was assessed using (i) Pearson's correlation coefficients, and (ii) partial correlation coefficients adjusted for age, sex and socioeconomic disadvantage. Survey weights and methods accounted for LSAC's complex sample design.

Results $20.7 \%$ of children were overweight and $6.2 \%$ obese, as were $33.5 \%$ and $31.6 \%$ of parents. Boys and girls showed similar distributions for all body composition measures but, despite similar BMI and waist-to-height ratio, mothers had higher proportions of total and truncal fat than fathers. Parent-child partial correlations were greatest for height $(0.37,95 \% \mathrm{Cl} 0.33$ to 0.42$)$. Other anthropometric and fat/lean measures showed strikingly similar partial correlations, ranging from $0.25(95 \% \mathrm{Cl}$ 0.20 to 0.29$)$ for waist circumference to $0.30(95 \% \mathrm{Cl}$ 0.25 to 0.34 ) for fat-free percentage. Whole-sample and sex-specific percentile values are provided for all measures.

Conclusions Excess adiposity remains prevalent in Australian children and parents. Moderate crossgenerational concordance across all measures of leanness and adiposity is already evident by late childhood.
Strengths and limitations of this study

- The nation-wide, population-based cohort was recruited using a two-stage random sampling design, enhancing generalisability of estimates.

- Multiple body composition attributes were objectively measured in children and parents, including body mass index and more detailed measures of segmental fat and fat-free mass and distribution from bioelectrical impedance analysis.

- Only one parent of each child was included in the cross-generational concordance analyses, so we cannot formally estimate heritability.

- Our parent sample comprised mostly mothers, so estimates of fathers' body composition are less precise.

- Our findings may not generalise to Australian adults who are not parents.

\section{INTRODUCTION}

While the proximal cause of overweight is a sustained energy imbalance, overweight clusters in families and clearly both genetic heritability and shared environmental factors contribute to this clustering. Although genetic polymorphisms associated with body composition are being identified, ${ }^{1}{ }^{2}$ the degree of heritability of body mass index (BMI) between parents and children is surprisingly unclear, with estimates ranging from 0.21 to 0.81 between studies. ${ }^{3}$ Likewise, parent-child concordance (reflecting both shared genetic and environmental contributions) in two key drivers of body composition-physical activity $^{4}$ and dietary patterns ${ }^{5}$ - have shown substantial heterogeneity between cohorts in recent meta-analyses.

The epidemiology of obesity—and of body composition more broadly-continues to evolve rapidly. Following steep rises starting around 1980 in all age groups, ${ }^{6}$ childhood overweight and obesity has plateaued since 
around 2005 and increments in adults have slowed, but both remain at historically high levels. For example, 2014-15 Australian estimates are that 27\% of children aged $5-17$ years are overweight (including $7 \%$ obese), as are $63 \%$ of adults (including $28 \%$ obese), ${ }^{7}$ with nearly $60 \%$ of today's children likely be obese by age 35 years. ${ }^{8}$ Population dietary, eating, activity and fitness patterns also continue to evolve-all of which could impact lean and fat mass in different ways, and all of which show varying degrees of environmental and genetic influences.

It is therefore surprising that, while many studies have looked at individual body composition measures (most commonly BMI) in parent-child pairs, ${ }^{9-12}$ few have considered a broad range of whole-of-body and segmental body composition measures in a contemporary population-representative sample. Multiple measures are required as fat has differential health impacts depending on where it is deposited throughout the body, ${ }^{13}$ for example, abdominal fat measures (such as waist circumference and waistto-height ratio) more strongly predict cardiovascular and all-cause mortality than BMI. ${ }^{1415}$ The few studies with multiple body composition measures in both parents and children have assessed body fat using dual energy X-ray absorptiometry or skinfold thickness ${ }^{16-18}$ (used in research but not clinical settings). We have identified no parent-child concordance studies incorporating bioimpedence analysis (BIA, commonly used in population and household settings) for assessing body fat and lean tissue mass and distribution.

Parent-child correlations in body composition differ by sex, parent and offspring ages, and specific aspect of body composition measured. ${ }^{3}$ Height (correlation coefficient (CC) 0.29 to 0.51$)^{9161719}$ and fat-free mass (CC 0.21 to 0.48$)^{1720}$ may be more strongly correlated than BMI (CC 0.19 to 0.44$)^{1017-22}$ and weight (CC 0.29 to $0.42),{ }^{101722}$ although estimates vary and overlap to a great extent between studies. Estimates of parent-child correlation on measures of body fat are slightly lower but again overlap with all other measures (body fat percentage CC 0.23 to $0.34,{ }^{1720}$ waist circumference CC 0.14 to $0.32^{19-21}$ and fat mass CC 0.16 to 0.30$).{ }^{1720}$ Longitudinal studies with repeated parent-child BMI concordance report that associations strengthen with child age (from CC 0.15 to 0.28 between ages 5 and $9,{ }^{9} \mathrm{CC} 0.25$ to 0.34 between ages $6-9$ and $10-11,{ }^{22}$ CC 0.31 to 0.36 between ages $9-10$ and $15-16^{18}$ and CC 0.33 to 0.43 between ages 15 and 22 years $^{23}$ ), presumably reflecting puberty-related changes towards a more adult-like physiology in the offspring. ${ }^{22}$ Offspring may not come to resemble parents more beyond this age; in the Midspan Family Study of Scottish parents aged 45-64 years and offspring at ages 30-59 years, regression coefficients for BMI concordance ranged from 0.26 to 0.35 depending on sex of parent and child. ${ }^{24}$ Several studies have reported mother-child concordance in BMI to be higher than father-child concordance, ${ }^{9}{ }^{11} 18$ postulating intrauterine environmental effects, but other studies report no difference ${ }^{1019}$ or stronger father-child associations. ${ }^{21}$ There is also mixed evidence for ${ }^{24} 25$ and against ${ }^{26}$ gender-assortative concordance in body composition, that is, a stronger association in mother-daughter and father-son pairs than mother-son and father-daughter pairs. Sex differences in the concordance of body compositional measures other than BMI remain relatively unexplored.

The Child Health CheckPoint, a cross-sectional biophysical wave nested within the Longitudinal Study of Australian Children (LSAC), provided an opportunity to include multiple measures of body composition in a broadly-focused health assessment of parent-child dyads at child age 11-12 years. Here, we aimed to describe, in a population-derived sample of Australian children aged 11-12years and their parents, (i) the epidemiology (population prevalence and distributional statistics) of body composition measures and (ii) parent-child concordance in these measures.

\section{METHODS}

\section{LSAC study design and participants}

Detailed information about the initial LSAC recruitment and study design is available elsewhere. ${ }^{27}{ }^{28}$ Briefly, a population-representative sample of children aged $0-1$ and 4-5years were recruited into LSAC's B and K cohort, respectively. A two-stage random sampling design was employed, using postcode as the primary sampling unit. For the B cohort, 8921 families were invited to participate, of which $5107(57.2 \%)$ were recruited into the first data collection wave in 2004. Additional data collection waves have occurred every 2 years since.

\section{CheckPoint study design and participant recruitment}

The Child Health CheckPoint was a physical health and biomarkers module offered to the $\mathrm{B}$ cohort between LSAC waves 6 and 7. The CheckPoint data collection spanned February 2015 to March 2016. During the 2014 wave 6 visit, $B$ cohort families $(n=3764)$ were introduced to the upcoming CheckPoint and asked to consent to their contact details being shared with the CheckPoint team. From late 2014, consenting families $(n=3513)$ received an information pack and recruitment phone call (figure 1). A more detailed description of the CheckPoint study design is available elsewhere. ${ }^{29} 30$

\section{Consent}

Parents provided informed written consent for their child's and their own study participation.

\section{Patient and public involvement}

Because LSAC is a population-based longitudinal study, no patient groups were involved in its design or conduct. To our knowledge, the public was not involved in the study design, recruitment or conduct of LSAC study or its CheckPoint module. Parents received a summary health report for their child and themselves at or soon after the CheckPoint assessment visit. They consented to take part 
LSAC Wave 1, 2004: $\mathrm{n}=5107$

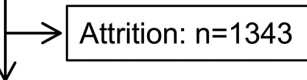

LSAC Wave 6, 2014: $\mathrm{n}=3764$

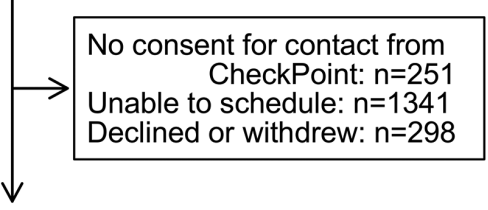

Child Health CheckPoint sample: $\mathrm{n}=1874$ (MAC $n=1356, m A C n=153, H V n=365$ )

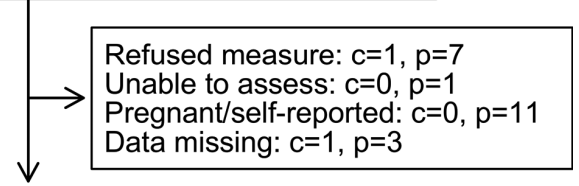

Body Composition data available for 1872 children and 1852 parents (1830 pairs)*

Figure 1 Participant flow. *Data from 20 nonbiological child-parent pairs excluded from concordance analyses. $\mathrm{c}=$ number of children; $\mathrm{HV}=$ Home visit assessment; LSAC= Longitudinal Study of Australian Children; $\mathrm{MAC}=$ Main assessment centre; $\mathrm{mAC}=$ Mini assessment centre; $n=$ number of families; $p=$ number of attending adults.

knowing that they would not otherwise receive individual results about themselves or their child.

\section{Procedure}

The main CheckPoint data collection mechanism was the 'pop-up' assessment centre. Families completed a 31/2 hour visit at an assessment centre set up sequentially in seven major Australian cities, or a $23 / 4$ hour visit at a mini-assessment centre set up in eight regional cities. Families unable to attend an assessment centre were offered a $1 \frac{1}{2}$ hour home visit. At the assessment centre, participants completed numerous measurements of multiple body systems in a standard sequence that differed slightly for children and parents. Participants advanced every 15 min from one station to the next, starting with the body composition station 'Measure Up'. Children and parents completed a brief questionnaire administered on an iPad using the Research Electronic Data Capture (REDCap) tool ${ }^{31}$ during downtime throughout the visit, or at the end of the visit.

\section{Measures}

Height, weight, BIA and waist circumference were measured at the beginning of the CheckPoint centre/ home visit, using standard protocols similar to previous LSAC waves (CheckPoint protocols are described in table 1). These data were used to derive BMI $\left(\mathrm{kg} / \mathrm{m}^{2}\right)$, total fat mass percentage, truncal fat percentage and waist-to-height ratio. For children, we also generated BMI and waist z-scores for age and sex using historical reference datasets. As child height, weight and waist circumference are expected to change throughout development, it is common practice within the paediatric literature to analyse z-scores, which allow tracking of an individual child's adiposity over time and comparison between children of different ages. The Measure $U p$ data collection and management standard operating procedures provide more detailed information (see http://checkpoint-lsac. mcri.edu.au).

An estimate of $300 \mathrm{~g}$ was subtracted from measured body weight for two children wearing a plaster cast. Two parents with pacemakers were weighed but BIA analysis was not conducted as the BIA electrical current may affect the operation of the device. Five pregnant women, and five parents who refused measurement but instead self-reported their height and weight, were excluded from our analyses.

Covariates: age and sex were self-reported in the questionnaire (parents) or LSAC provided these data exported from administrative databases (children). Neighbourhood socioeconomic disadvantage was linked to publicly available Australian Bureau of Statistics Census data. Child pubertal status was self-reported in the questionnaire. These covariates were measured at the CheckPoint visit (table 1); no LSAC data are analysed in this study.

\section{Statistical analysis}

For aim 1, we described the distributions of body composition domains in children and parents using mean values and SD, as well as key percentiles. These population summary statistics were calculated using weighted multilevel survey analyses that took clustering in the sampling frame and stratification into account. The analytic sample comprised all study children and attending parents (any adult who attended with the study child) with data for at least one measure of height, weight, BIA or waist circumference.

For aim 2, concordance between parents and children was quantified for (i) the sample overall and (ii) subgroups by child and parent sex, using Pearson's correlation coefficients (CC) with 95\% CIs, and partial correlation coefficients, adjusted for child and parent age, Disadvantage Index and for child and parent sex in models including both sexes; with $95 \%$ bootstrapped CIs. In addition, aim 2 analyses were repeated using weighted multilevel survey analyses. ${ }^{32}$ The unweighted and weighted results were similar, so we present the unweighted analyses. The aim 2 analytic sample consisted of all biological parent-child pairs with complete data for at least one measurement.

All analyses were performed using Stata V.14.2.

\section{RESULTS}

A total of 1874 parent-child pairs participated in the Child Health CheckPoint module. Figure 1 summarises 
Table 1 Study measures and protocols

Measure Equipment/instrument Data collection and data capture Data derivation

Body composition

Standing height ${ }^{45} 46$

Portable rigid

stadiometer (Invicta

IP0955, Leicester, UK)

\begin{tabular}{|c|c|}
\hline Weight and $\mathrm{BIA}^{4546}$ & $\begin{array}{l}\text { Four-limb segmental } \\
\text { body composition scales } \\
\text { (InBody230, Biospace, } \\
\text { Seoul, Korea). If not } \\
\text { available, two-limb body } \\
\text { composition scales } \\
\text { (Tanita BC-351, Kewdale, } \\
\text { Australia) }\end{array}$ \\
\hline
\end{tabular}

Derived from height and weight, above
In light clothing, without shoes or socks, participants stood straight with their heels, back and shoulders against the stadiometer and their head in the Frankfort plane. Height was measured twice (to nearest $0.1 \mathrm{~cm}$ ); a third measurement was taken if first two measures differed by $\geq 0.5 \mathrm{~cm}$. Staff recorded each height measurement into the participant's REDCap ${ }^{31}$ data entry form.

Participants wore light clothing and no shoes Four-limb BIA: or socks. Weight was measured once (to the nearest $0.1 \mathrm{~kg}$ ), and entered into REDCap. Staff entered participant ID, age, sex and mean height into the scales. BIA was measured once with the participant standing on the scale footplates (and also holding two horizontal handles, in the case of four-limb BIA).

Four-limb BIA: Staff entered weight and total body fat mass (to the nearest $0.1 \mathrm{~kg}$ ) into REDCap, and exported BIA data to USB daily.

Two-limb BIA: staff entered weight and total body fat percentage (to the nearest $0.1 \%$ ) kg) $\times 100$. $\mathrm{kg}) \times 100$.

Two-limb BIA: fat $\%) / 100$ total fat in $\mathrm{kg}$
Body mass index

(BMI), z-scores and into REDCap.

Total body fat \%: (total fat in $\mathrm{kg} /$ weight in

Total body fat-free mass \%: ((weight in kgtotal fat in $\mathrm{kg}$ )/weight in $\mathrm{kg}$ ) $\times 100$.

Truncal fat \%: (truncal fat in $\mathrm{kg} /$ weight in

Non-truncal fat \%: (right arm+left arm+right leg+leftleg fat in $\mathrm{kg}$ )/ weight in $\mathrm{kg}) \times 100$.

Total body fat in $\mathrm{kg}$ : (weight in kgxtotal body

Total body fat-free mass in $\mathrm{kg}$ : weight in $\mathrm{kg}$

Total body fat-free mass \%: as above.

Two-limb scales did not generate segmental body composition information.

BMI: weight in $\mathrm{kg} /\left(\right.$ mean height in $\left.\mathrm{cm}^{2}\right)$.

$B M I$ z-score (children only): BMI transformed into z-scores using both $\mathrm{CDC}^{47}$ and $\mathrm{UK}^{4} \mathrm{O}^{48}$ population normative data.

Weight status: BMI categorised into underweight, normal weight, overweight and obese using IOTF cut-points for children, ${ }^{49}$ and $\mathrm{WHO}$ cut-points for adults. ${ }^{50}$

\begin{tabular}{|c|c|}
\hline $\begin{array}{l}\text { Waist } \\
\text { circumference }{ }^{45} 46\end{array}$ & $\begin{array}{l}\text { Steel anthropometric } \\
\text { measuring tape (Lufkin } \\
\text { Executive Diameter } \\
\text { W606PM, Maryland, } \\
\text { USA) }\end{array}$ \\
\hline
\end{tabular}

Waist circumference was measured twice on the skin (to the nearest $0.1 \mathrm{~cm}$ ), at the narrowest point between the 10th rib and iliac crest. If no narrowing was present, the measurement was taken at the midpoint between these two landmarks. A third measure was taken if the first two measures differed by $\geq 1 \mathrm{~cm}$. Staff recorded each waist measurement into REDCap.

\section{Mean waist circumference: average of all} measurements.

Waist circumference z-score (children only): waist circumference transformed into $z$-score using the UK90 $0^{51}$ population normative data. Waist-to-height ratio: mean waist circumference in $\mathrm{cm} /$ mean height in $\mathrm{cm}$.

\section{Potential confounders}

$\begin{array}{llll}\text { Age } & \begin{array}{l}\text { Children: Medicare } \\ \text { Australia database } \\ \text { Parents: self-reported }\end{array} & \begin{array}{l}\text { Children: LSAC provided DOB, which } \\ \text { was originally exported from the Medicare } \\ \text { Australia database. } \\ \text { Parents: self-reported in the CheckPoint } \\ \text { questionnaire. }\end{array} & \begin{array}{l}\text { Age in years: (date of CheckPoint } \\ \text { assessment-DOB)/365. }\end{array} \\ \text { Sex } & \begin{array}{l}\text { Children: Medicare } \\ \text { Australia database } \\ \text { Parents: self-reported }\end{array} & \begin{array}{l}\text { Children: LSAC provided sex, which was } \\ \text { originally exported from the Medicare } \\ \text { Australia database. } \\ \text { Parents: self-reported in the CheckPoint } \\ \text { questionnaire. }\end{array} & \text { Data used as collected. }\end{array}$

Continued 
Table 1 Continued

\begin{tabular}{|c|c|c|c|}
\hline Measure & Equipment/instrument & Data collection and data capture & Data derivation \\
\hline $\begin{array}{l}\text { Pubertal status } \\
\text { (children only) }\end{array}$ & $\begin{array}{l}\text { Pubertal Development } \\
\text { Scale. }^{52}\end{array}$ & $\begin{array}{l}\text { Five questions about the pubertal } \\
\text { development: growth spurt, body hair } \\
\text { growth, skin changes/pimples, deepening } \\
\text { of voice (male version only), facial hair (male } \\
\text { version only), breast growth (female version } \\
\text { only) and menstruation (female version only). } \\
\text { Four-point response scale: 'has not started } \\
\text { yet' (coded as 1) 'has barely started' (2), 'has } \\
\text { definitely started' (3) and 'seems complete' } \\
\text { (4). }\end{array}$ & $\begin{array}{l}\text { Boys: responses were summed for body hair, } \\
\text { deepening of voice and facial hair responses, } \\
\text { then grouped into pubertal development } \\
\text { categories: prepubertal (3), early pubertal } \\
(4,5) \text {, midpubertal (6-8) or late postpubertal } \\
(9-12) \text {. } \\
\text { Girls: body hair and breast growth responses } \\
\text { summed. Pubertal categories created using } \\
\text { score and menstruation response: prepubertal } \\
\text { ( } 2 \text {, not yet menstruating), early pubertal ( } 3 \text {, not } \\
\text { yet menstruating), midpubertal ( } \geq 4 \text {, not yet } \\
\text { menstruating), late postpubertal (menstruation } \\
\text { started). }\end{array}$ \\
\hline Disadvantage Index & $\begin{array}{l}\text { Socio-Economic Indexes } \\
\text { for Areas Index of } \\
\text { Relative Socioeconomic } \\
\text { Disadvantage } 2011 \\
\text { (Disadvantage Index) }^{53}\end{array}$ & $\begin{array}{l}\text { LSAC provided contact details of families } \\
\text { consenting to be contacted by CheckPoint. } \\
\text { The family's residential postcode was } \\
\text { confirmed during the CheckPoint recruitment } \\
\text { phone call and updated, if required. }\end{array}$ & $\begin{array}{l}\text { The Disadvantage Index score of postcode } \\
\text { was used to summarise neighbourhood } \\
\text { socioeconomic position. Generated by the } \\
\text { ABS from the } 2011 \text { national Census, the } \\
\text { index numerically summarises the social } \\
\text { and economic conditions of Australian } \\
\text { neighbourhoods; national mean } 1000, \text { SD }_{100} 100 \\
\text { higher scores indicate less disadvantage. }\end{array}$ \\
\hline
\end{tabular}

ABS, Australian Bureau of Statistics; BIA, bioimpedence analysis; BMI, body mass index; CDC, Centres for Disease Control and Prevention; DOB, date of birth; IOTF, International Obesity Task Force; LSAC, Longitudinal Study of Australian Children; REDCap; Research Electronic Data Capture; UK90, United Kingdom 1990; USB, universal serial bus.

the sample size and reasons for non-response at various stages of the study, and reasons for missing body composition data within the CheckPoint module. Data for at least one body composition measure are available for 1872 children and 1852 parents, including 1830 biological parent-child pairs.

There was a similar proportion of boys and girls, but $88 \%$ of parents were mothers (table 2). The average age of children was 12.0 years, and fathers were 3 years older than mothers, on average. A greater proportion of girls $(89 \%)$ than boys $(48 \%)$ were in the mid-late stages of pubertal development. The sample was somewhat less socioeconomically disadvantaged than the general population, with $26 \%$ of the sample in the least disadvantaged national quintile but only $12 \%$ in the most disadvantaged quintile.

\begin{tabular}{|c|c|c|c|}
\hline Characteristic & All & Male & Female \\
\hline Child & $n=1731-1872$ & $n=898-954$ & $n=833-918$ \\
\hline Age, years & $12.0(0.4)$ & $12.0(0.4)$ & $12.0(0.4)$ \\
\hline \multicolumn{4}{|l|}{ Pubertal status, $\%$} \\
\hline Prepubertal & 8.5 & 12.0 & 4.5 \\
\hline Early pubertal & 24.4 & 40.0 & 6.7 \\
\hline Mid-pubertal & 52.5 & 42.2 & 64.1 \\
\hline Late postpubertal & 14.6 & 5.8 & 24.6 \\
\hline Parent & $n=1847-1852$ & $n=226-229$ & $n=1621-1623$ \\
\hline Age, years & $43.7(5.6)$ & $46.4(7.1)$ & $43.3(5.3)$ \\
\hline Disadvantage index & $1009(61)$ & $1005(69)$ & $1009(61)$ \\
\hline \multicolumn{4}{|c|}{ Disadvantage index quintile, \% } \\
\hline 1 (most disadvantaged) & 12.3 & 13.8 & 12.2 \\
\hline 2 & 18.1 & 22.7 & 17.5 \\
\hline 3 & 21.3 & 21.9 & 21.2 \\
\hline 4 & 22.6 & 14.9 & 23.7 \\
\hline 5 (least disadvantaged) & 25.6 & 26.7 & 25.5 \\
\hline
\end{tabular}

Sample weights applied to data. 
Approximately one-quarter of children and two-thirds of parents were overweight or obese (children: overweight $20.7 \%$, obese $6.2 \%$; parents: overweight $33.5 \%$, obese $31.6 \%$ ). Table 3 shows that, compared with fathers, mothers had a mean waist circumference approximately $12 \mathrm{~cm}$ less, similar waist-to-height ratio and BMI and higher proportions of total body fat (36\% compared with $26 \%$ ) and truncal fat (18\% compared with 14\%). Sex differences in these measures were much smaller in children. In regard to fat distribution, children had a greater proportion of their fat in the non-truncal regions than adults.

The distributions of BMI, waist circumference, total body fat mass and truncal fat mass are plotted in figures 2 and 3. For reference purposes, online supplementary table 1 shows the distribution of these body composition markers at key percentiles (from 5th to 95th). Among children, there were no notable sex differences in the distribution of BMI or waist z-scores, but the distribution of total and truncal fat was slightly shifted to the right (ie, greater proportion of fat) in girls compared with boys.

Adults showed more striking sex differences. While mothers' and fathers' mean BMI were similar (table 3), the distribution in mothers was flatter and shifted to the left (ie, lower BMI) compared with fathers. The distribution of men's and women's waist circumference were similar in shape, but shifted to the left (ie, smaller waists) in women. Australian guidelines recommend waist circumference below 94 and $80 \mathrm{~cm}$ cut-points for men and women, respectively. ${ }^{33} 34$ The median waist circumference for men and women exceeded these cut-points (online supplementary table 1 ), that is, $57 \%$ (95\% CI 50 to 65 ) of men and $61 \%$ (95\% CI 58 to 63 ) of women in the parent sample exceeded recommendations.

Mothers and fathers had different distributions of total body and truncal fat mass. The mothers had a wider range of fat than fathers, and the distribution was shifted to the right (ie, greater proportion of fat mass). Overlap in the distributions of mothers' and fathers' fat was less than for other body composition measures.

Unadjusted correlations between child and parent body composition in the cohort overall were moderate and remarkably consistent (table 4); concordance was highest for height (CC 0.30 , 95\% CI 0.25 to 0.34 ) and lowest for waist circumference (CC 0.23 , 95\% CI 0.19 to 0.28 ). Table 4 also shows that mother-child and father-child correlations were similar for each measure, although there was a tendency for father-child waist, fat and fat-free mass estimates to be higher (but with wider CIs) than mother-child correlations. While we did not conduct formal statistical tests, sex-matched pairs (ie, mother-daughter, father-son) appeared to show similar concordance to sex-mixed pairs (ie, mother-son, fatherdaughter; online supplementary table 2).

On adjustment for age, sex and Disadvantage Index, parent-child height correlations strengthened to be clearly greater than the remaining correlations, which remained relatively unchanged and tightly clustered.

\section{DISCUSSION}

\section{Principal findings}

We describe the epidemiology of BMI, waist, fat and fat-free mass measures in a large population-based Australian cohort of parents and children, at two stages of the life course (11-12 years of age and mid-adulthood). A quarter of children and two-thirds of adults were overweight or obese on BMI criteria. We confirm known sex differences between men's and women's body composition. ${ }^{35}$ Parent-child concordance in body composition measures were moderate and strikingly similar for all measures tapping into leanness and adiposity, with partial correlations ranging from 0.25 to 0.30 ; the exception was higher concordance for height (0.37). Mother-child and father-child concordance patterns were similar, although estimates appeared slightly stronger for fathers than for mothers.

\section{Strengths and weaknesses of the study}

Body composition was measured in a large nationwide cohort of children and their parents originally selected to be population-representative. ${ }^{37}$ Dyads underwent multiple measures of body composition at the same time and using the same equipment and protocols, maximising generalisability and minimising biases reflecting these factors. Our BIA scales captured segmental, as well as whole-of-body, fat mass. Although the smaller numbers of fathers reduced the precision of father-child estimates, this is one of few studies to provide population estimates both for mother-child and father-child concordance for any anthropometric measurement.

Limitations included under-representation of very disadvantaged families due to selective uptake of CheckPoint and attrition in LSAC, partly mitigated by our use of survey weights (although this showed no meaningful influence on the results). We cannot extend conclusions outside the narrow child age range (11-12 years) and, as we examined parent-child dyads rather than triads, we cannot formally estimate heritability.

\section{Comparisons with other studies}

As expected, exact estimates vary across different samples, however, our results are very similar to recent local studies. The prevalence of overweight and obesity in our child $(27 \%)$ and parent $(65 \%)$ samples were similar to those reported in the 2014-15 Australian National Health Survey (27\% of children aged 5-17years and $63 \%$ of adults aged $18+$ years) 3 years earlier. ${ }^{7}$ Our child waist circumference (mean $66.9 \mathrm{~cm}$, SD $9.0 \mathrm{~cm}$ ) was slightly smaller than that of the Australian children 11-12 years measured in the 2007 National Children's Nutrition and Physical Activity survey (mean $69.1 \mathrm{~cm}, \mathrm{SD} 10.3 \mathrm{~cm}$; unpublished data, provided by co-author TO). Fifty-seven per cent (95\% CI 50 to 65) of our fathers and $61 \%$ (95\% CI 58 to 63) of our mothers exceeded the recommended waist cut-points of 94 and $80 \mathrm{~cm}$ cut-points for men and women, respectively, ${ }^{334}$ compared with $60 \%$ of Australian men and $65 \%$ of women aged $\geq 18$ years in the 2014-15 


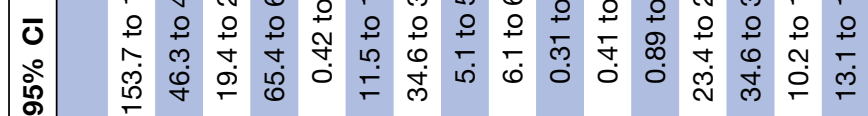

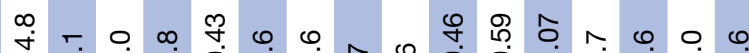
苛

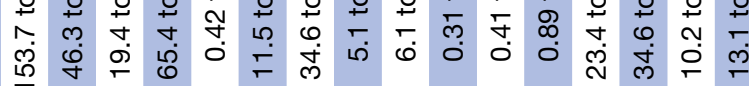

क

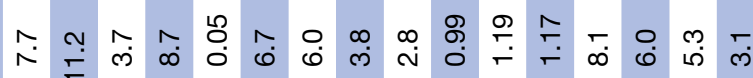

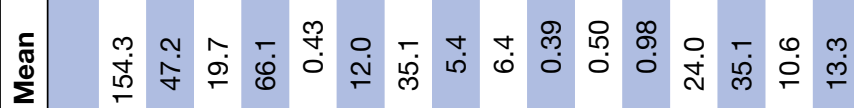
这 б ભூ ก̂

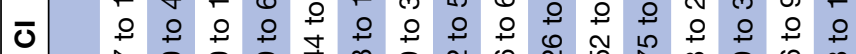
苚

ค ฯ

焉

$\frac{\mathscr{d}}{\mathfrak{\pi}}$

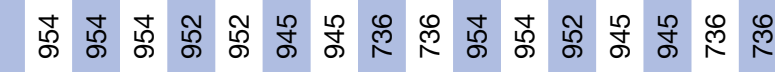

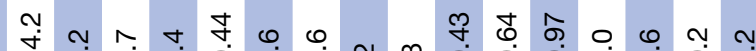
苟 年 J $\quad$ ○ - $\quad$ क

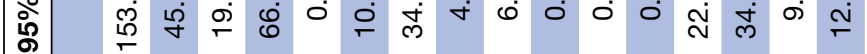

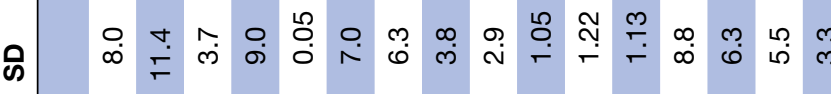

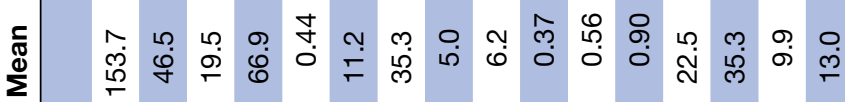

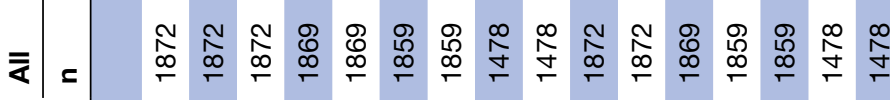

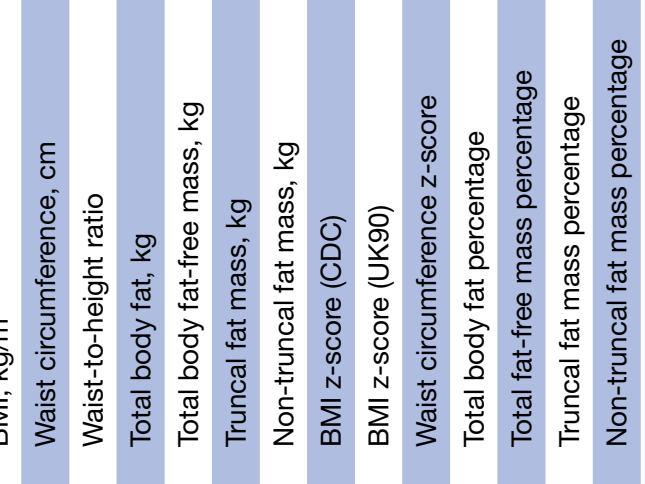

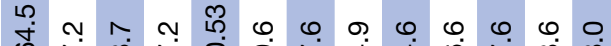

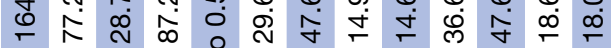

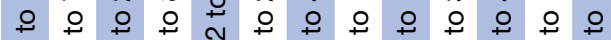
药

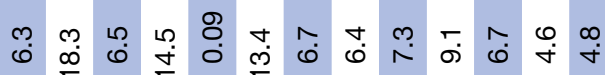

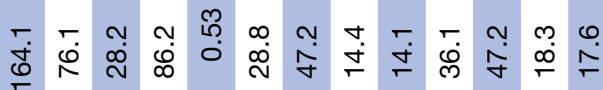

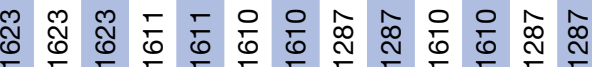
๑) m

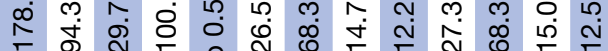
아의

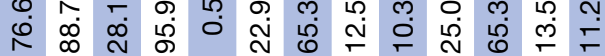

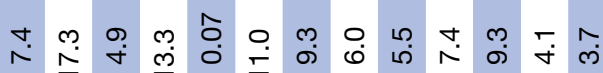

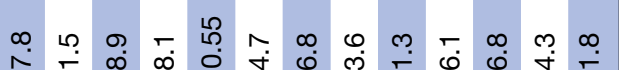
奌

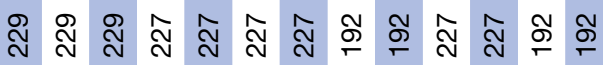
ก

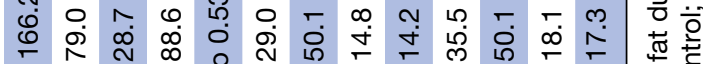

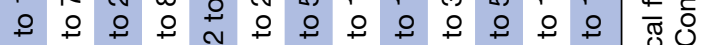

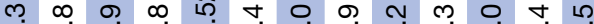
ঠீ丨

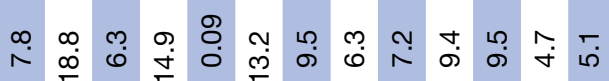
के ^.

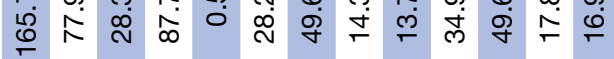

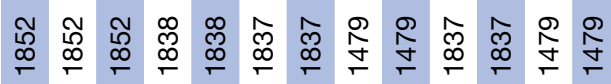

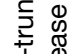
$\frac{\pi}{2}$ 空 高 N $\frac{0}{2} \frac{\mathbb{2}}{\mathrm{O}}$ రั 응 중 蒫

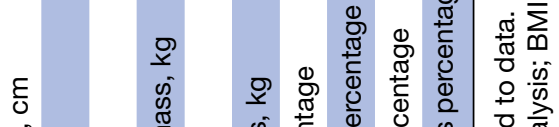

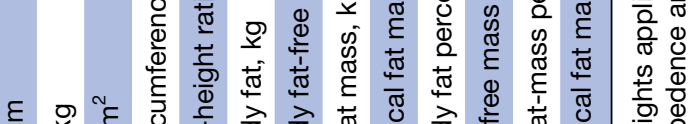

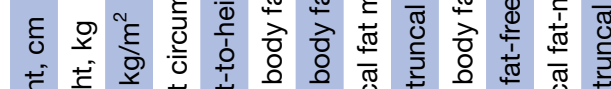
这 을

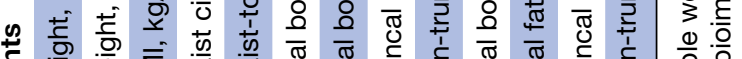

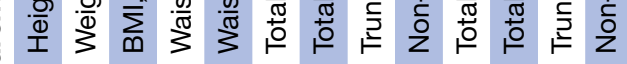
焉 $\frac{1}{\infty}$ 

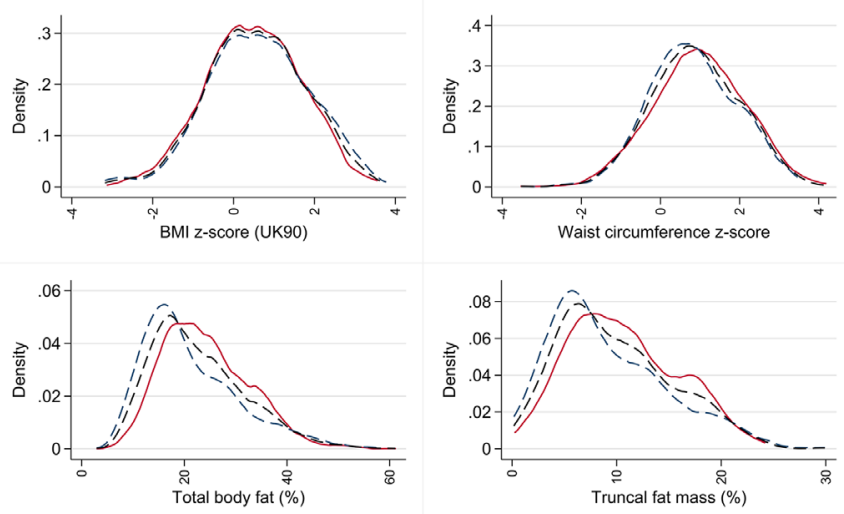

$$
\begin{array}{|ll|}
\hline- \text { Girl } & ----- \text { Boy } \\
\hline--- \text { All children } &
\end{array}
$$

Figure 2 Distribution of child body composition measures. Sample weights applied to data. BMI, body mass index; UK90, United Kingdom 1990.

survey. Total body fat percentage in our child sample are similar to, but slightly higher than, values reported for the children aged 9-11 years in the Australian subsample of the 2011-13 International Study of Childhood Obesity, Lifestyle and Environment (ISCOLE) study. ${ }^{38} 39$

As previous studies have examined parent-child concordance in a single or limited number of body composition measures, ours is one of the first to show the consistency in concordance (CC 0.23 to 0.30 ) across a broad range of body composition measures spanning leanness to adiposity. Our concordance estimates generally fell within the ranges previously reported for each measure, except that our concordance for height fell on the lower end of the range, ${ }^{9}$ and weight just below the lower boundary reported in previous literature..$^{91016-22}$ Previous studies collectively show parent-child concordance in BMI strengthens with child age; our estimate of 0.29 at child age 11-12 years is consistent with previous estimates of 0.31 to 0.34 for children aged $9-10$ and $10-11$ years, respectively. ${ }^{182}$
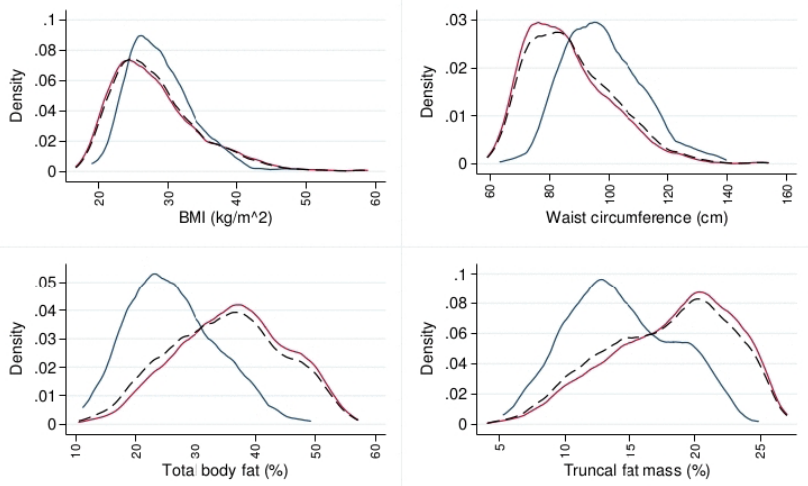

$$
\begin{array}{ll}
- & \text { Mother } \\
----- \text { All adults }
\end{array}
$$

Figure 3 Distribution of parent body composition measures. Sample weights applied to data. BMI, body mass index.

\section{Meaning and implications for clinicians and policymakers}

This study updates summary population data on multiple body composition measures across two generations. Prevalence data for overweight and obesity are not novel, but contribute to within-country and between-country population monitoring. Population monitoring should track a range of body composition measures, not BMI alone, as these may have independent health benefits (eg, lean mass) and risk (eg, truncal fat) and can vary in the face of stable BMI in children ${ }^{40}$ and adults. ${ }^{41}$ This dataset is available to researchers from early-2019 (see the data sharing statement at the end of the article). Uses may include statistical power calculation and exploration of the shared and unique contributions of each of the body composition measures to outcomes of choice, to inform which of the multiple measures would be most appropriate for future trials.

Taken with other studies, our moderate concordances support both genetic and environmental influences on body composition measures. Older children share only some of the latter with their parents. On the one hand, parents are to some extent nutritional gatekeepers for their children; on the other, children spend a substantial amount of time at school and with peers, in homogenising environments not shared with their parents. While extreme environmental restrictions (such as body building, gastric banding ${ }^{42}$ and the Cuban blockade ${ }^{43}$ ) show very real malleability of body composition, longterm change is nonetheless profoundly difficult for most individuals. ${ }^{44}$ Given that each aspect of body composition likely falls under different genetic influences, it is striking that our parent-child concordances across all body compartments were nearly identical (except for height, known to be strongly genetically influenced). The modest concordances between parents and children may challenge a general pessimism about the ability of children to follow healthier trajectories than their overweight parents, and suggest that far more than the family environment drives the current obesity epidemic.

\section{Unanswered questions and future research}

Establishing national and international repositories of representative body composition data would allow nearreal time detection of shifts in prevalence in response to policy changes and other levers, and support future healthcare provision and economic modelling. The ultimate goal remains interventions-whether driven by politics, policy or practice-that reduce obesity and lead to healthier body composition. Unfortunately, at the present time, the 'optimal' body composition at differing stages of the lifecourse remains unknown as it relates to a range of important outcomes. Defining this requires large longitudinal population studies incorporating family triads, biospecimens and relevant exposures and disease outcomes/proxies, including the potential for Mendelian randomisation studies. Novel intervention strategies may be informed by parents and children non-concordant for adiposity. 


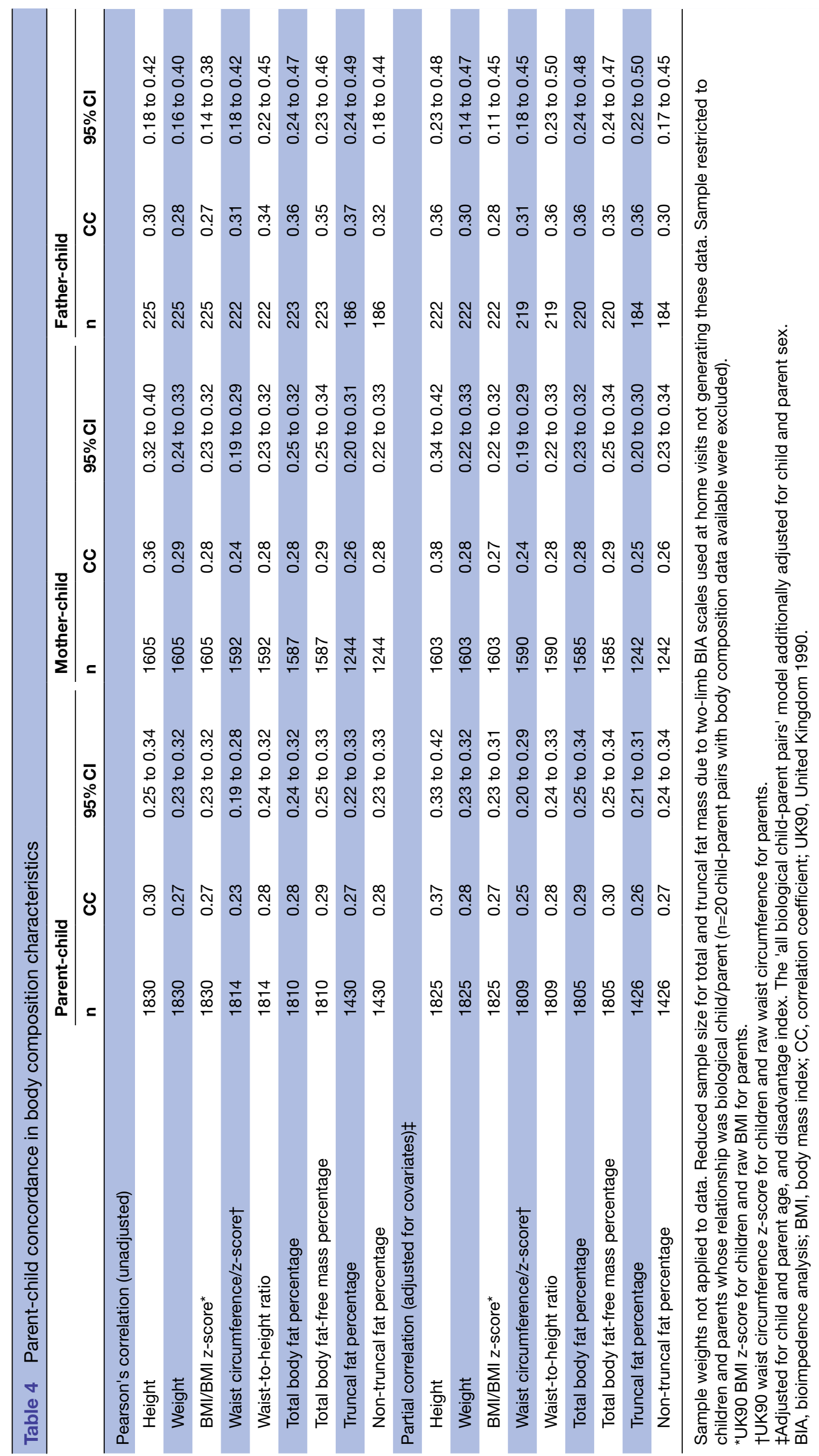


Acknowledgements This paper uses unit record data from Growing Up in Australia, the Longitudinal Study of Australian Children. The study is conducted in partnership between the Department of Social Services (DSS), the Australian Institute of Family Studies (AIFS) and the Australian Bureau of Statistics (ABS). Research Electronic Data Capture (REDCap) electronic data capture tools were used in this study. More information about this software can be found at: www. project-redcap.org. The authors would like to thank the LSAC and CheckPoint study participants, staff and students for their contributions. The authors would also like to thank Dr Katherine Lange for her assistance with the figures and analyses.

Contributors SC is the CheckPoint's Project Manager, and refined the analysis plan and drafted the initial manuscript. ANG is a study research assistant, and refined the analysis plan and drafted the initial manuscript. TO is a study investigator involved in the conception and oversight of the Child Health CheckPoint, and provided expert advice and critical review of this manuscript. ACG is a study biostatistician, and conducted and refined the analyses and provided critical review of this manuscript. MW is the Principal Investigator of the Child Health CheckPoint, and provided expert advice and critical review of this manuscript.

Funding This work was supported by the National Health and Medical Research Council (NHMRC) of Australia (Project Grants 1041352, 1109355), The Royal Children's Hospital Foundation (2014-241), the Murdoch Children's Research Institute (MCRI), The University of Melbourne, the National Heart Foundation of Australia (100660) and the Financial Markets Foundation for Children (2014055, 2016-310). MW was supported by the NHMRC (Senior Research Fellowship 1046518) and Cure Kids New Zealand. The MCRI administered the research grants for the study and provided infrastructural support (IT and biospecimen management) to its staff and the study, but played no role in the conduct or analysis of the trial. The Department of Social Services played a role in study design; however, no other funding bodies had a role in the study design and conduct; data collection, management, analysis and interpretation; preparation, review or approval of the manuscript; and decision to submit the manuscript for publication. Research at the MCRI is supported by the Victorian Government's Operational Infrastructure Support Program.

Disclaimer The findings and views reported in this paper are those of the author and should not be attributed to DSS, AIFS or the ABS.

Competing interests All authors have completed the ICMJE uniform disclosure form at www.icmje.org/coi_disclosure.pdf and declares financial support as described in the funding section.

Patient consent for publication Not required.

Ethics approval The Child Health CheckPoint study protocol was approved by The Royal Children's Hospital, Melbourne, Human Research Ethics Committee (33225D) and Australian Institute of Family Studies Ethics Committee (14-26).

Provenance and peer review Not commissioned; externally peer reviewed.

Data sharing statement The Longitudinal Study of Australian Children datasets and technical documents are available to researchers at no cost via a licence agreement. Data access requests are co-ordinated by the National Centre for Longitudinal Data. More information is available at https://dataverse.ada.edu.au/ dataverse/lsac.

Open access This is an open access article distributed in accordance with the Creative Commons Attribution Non Commercial (CC BY-NC 4.0) license, which permits others to distribute, remix, adapt, build upon this work non-commercially, and license their derivative works on different terms, provided the original work is properly cited, appropriate credit is given, any changes made indicated, and the use is non-commercial. See: http://creativecommons.org/licenses/by-nc/4.0/.

\section{REFERENCES}

1. Albuquerque D, Stice E, Rodríguez-López R, et al. Current review of genetics of human obesity: from molecular mechanisms to an evolutionary perspective. Mol Genet Genomics 2015;290:1191-221.

2. Hebebrand J, Volckmar AL, Knoll N, et al. Chipping away the 'missing heritability': GIANT steps forward in the molecular elucidation of obesity - but still lots to go. Obes Facts 2010;3:294-303.

3. Elks CE, den Hoed M, Zhao JH, et al. Variability in the heritability of body mass index: a systematic review and meta-regression. Front Endocrinol 2012;3:29.

4. Yao CA, Rhodes RE. Parental correlates in child and adolescent physical activity: a meta-analysis. Int J Behav Nutr Phys Act 2015;12:10.
5. Wang Y, Beydoun MA, Li J, et al. Do children and their parents eat a similar diet? Resemblance in child and parental dietary intake: systematic review and meta-analysis. J Epidemiol Community Health 2011;65:177-89.

6. $\mathrm{Ng} \mathrm{M}$, Fleming $\mathrm{T}$, Robinson $\mathrm{M}$, et al. Global, regional, and national prevalence of overweight and obesity in children and adults during 1980-2013: a systematic analysis for the Global Burden of Disease Study 2013. Lancet 2014;384:766-81.

7. Australian Bureau of Statistics. National Health Survey: first results, Australia, 2014-15: Australian Bureau of Statistics, 2015.

8. Ward ZJ, Long MW, Resch SC, et al. Simulation of growth trajectories of childhood obesity into adulthood. N Engl J Med 2017;377:2145-53.

9. Kelly GE, Murrin C, Viljoen K, et al. Body mass index is associated with the maternal lines but height is heritable across family lines in the Lifeways Cross-Generation Cohort Study. BMJ Open 2014;4:e005732.

10. Davey Smith G, Steer C, Leary S, et al. Is there an intrauterine influence on obesity? Evidence from parent child associations in the Avon Longitudinal Study of Parents and Children (ALSPAC). Arch Dis Child 2007;92:876-80.

11. Lawlor DA, Smith GD, O'Callaghan M, et al. Epidemiologic evidence for the fetal overnutrition hypothesis: findings from the MaterUniversity Study of Pregnancy and its Outcomes. Am J Epidemiol 2007;165:418-24.

12. Power C, Pouliou T, Li L, et al. Parental and offspring adiposity associations: insights from the 1958 British birth cohort. Ann Hum Biol 2011;38:390-9.

13. Jensen MD. Role of body fat distribution and the metabolic complications of obesity. J Clin Endocrinol Metab 2008;93(11 Suppl 1):s57-63.

14. Petursson $\mathrm{H}$, Sigurdsson JA, Bengtsson $\mathrm{C}$, et al. Body configuration as a predictor of mortality: comparison of five anthropometric measures in a 12 year follow-up of the Norwegian HUNT 2 study. PLoS One 2011;6:e26621.

15. Song $X$, Jousilahti $P$, Stehouwer $C D$, et al. Comparison of various surrogate obesity indicators as predictors of cardiovascular mortality in four European populations. Eur J Clin Nutr 2013;67:1298-302.

16. Ajala O, Fr Meaux AE, Hosking J, et al. The relationship of height and body fat to gender-assortative weight gain in children. A longitudinal cohort study (EarlyBird 44). Int J Pediatr Obes 2011;6(3-4):223-8.

17. Treuth MS, Butte NF, Ellis KJ, et al. Familial resemblance of body composition in prepubertal girls and their biological parents. Am J Clin Nutr 2001;74:529-33.

18. Lawlor DA, Benfield L, Logue J, et al. Association between general and central adiposity in childhood, and change in these, with cardiovascular risk factors in adolescence: prospective cohort study. BMJ 2010;341:c6224.

19. Heude B, Kettaneh A, Rakotovao R, et al. Anthropometric relationships between parents and children throughout childhood: the Fleurbaix-Laventie Ville Santé Study. Int J Obes 2005;29:1222-9.

20. Chaput JP, Pérusse L, Després JP, et al. Findings from the Quebec Family Study on the Etiology of Obesity: genetics and environmental highlights. Curr Obes Rep 2014;3:54-66.

21. Brandt S, Moß A, Koenig W, et al. Intrafamilial associations of cardiometabolic risk factors--results of the Ulm Birth Cohort Study. Atherosclerosis 2015;240:174-83.

22. Halvorsen T, Moran A, Jacobs DR, et al. Relation of cardiometabolic risk factors between parents and children. $J$ Pediatr 2015;167:1049-56.

23. Frohnert BI, Jacobs DR, Steinberger J, et al. Relation between serum free fatty acids and adiposity, insulin resistance, and cardiovascular risk factors from adolescence to adulthood. Diabetes 2013;62:3163-9.

24. Han TS, Hart CL, Haig C, et al. Contributions of maternal and paternal adiposity and smoking to adult offspring adiposity and cardiovascular risk: the Midspan Family Study. BMJ Open 2015;5:e007682

25. Mostazir M, Jeffery A, Voss L, et al. Gender-assortative waist circumference in mother-daughter and father-son pairs, and its implications. An 11-year longitudinal study in children (EarlyBird 59). Pediatr Obes 2014;9:176-85.

26. Patel R, Martin RM, Kramer MS, et al. Familial associations of adiposity: findings from a cross-sectional study of 12,181 parentaloffspring trios from Belarus. PLoS One 2011;6:e14607.

27. Edwards B. Growing Up in Australia: The Longitudinal Study of Australian Children: Entering adolescence and becoming a young adult. Family Matters 2014;95:5-14.

28. Sanson A, Johnstone R. The LSAC Research Consortium \& FaCS LSAC Project Team. Growing Up in Australia takes its first steps. Family Matters 2004;67:46-53. 
29. Wake M, Clifford SA, York E, et al. Introducing Growing Up in Australia's Child Health CheckPoint. Family Matters 2014;95:15-23.

30. Clifford SA, Davies S, Wake M, et al. Child Health CheckPoint: Cohort summary and methodology of a physical health and biospecimen module for the Longitudinal Study of Australian Children. BMJ Open 2019;9(suppl 3):3-22.

31. Harris PA, Taylor R, Thielke R, et al. Research electronic data capture (REDCap)--a metadata-driven methodology and workflow process for providing translational research informatics support. J Biomed Inform 2009;42:377-81.

32. Ellul S, Hiscock R, Mensah FK, et al. Longitudinal Study of Australian Children's Child Health CheckPoint Technical Paper 1: Weighting and Non-Response. Melbourne, Australia: Murdoch Children's Research Institute, 2018.

33. National Health and Medical Research Council. Clinical Practice Guidelines for the Management of Overweight and Obesity in Adults, Adolescents and Children in Australia. Melbourne: NHMRC, 2013.

34. World Health Organization. Obesity: Preventing and managing the global epidemic. Geneva, Switzerland: World Health Organization, 2000.

35. Heo M, Faith MS, Pietrobelli A, et al. Percentage of body fat cutoffs by sex, age, and race-ethnicity in the US adult population from NHANES 1999-2004. Am J Clin Nutr 2012;95:594-602.

36. Wells JC. Sexual dimorphism of body composition. Best Pract Res Clin Endocrinol Metab 2007;21:415-30.

37. Soloff C, Lawrence D, Johnstone R. LSAC technical paper number 1: Sample design. Melbourne: Australian Institute of Family Studies, 2005.

38. Zakrzewski JK, Gillison FB, Cumming S, et al. Associations between breakfast frequency and adiposity indicators in children from 12 countries. Int J Obes Supp/ 2015;5(Suppl 2):S80-8.

39. Broyles ST, Denstel KD, Church TS, et al. The epidemiological transition and the global childhood obesity epidemic. Int J Obes Suppl 2015;5(Suppl 2):S3-8.

40. Fernández JR, Bohan Brown M, López-Alarcón M, et al. Changes in pediatric waist circumference percentiles despite reported pediatric weight stabilization in the United States. Pediatr Obes 2017;12:347-55.
41. Lao XQ, Ma WJ, Sobko T, et al. Overall obesity is leveling-off while abdominal obesity continues to rise in a Chinese population experiencing rapid economic development: analysis of serial crosssectional health survey data 2002-2010. Int J Obes 2015;39:288-94.

42. Cunneen SA. Review of meta-analytic comparisons of bariatric surgery with a focus on laparoscopic adjustable gastric banding. Surg Obes Relat Dis 2008;4(3 Suppl):S47-55.

43. Franco M, Bilal U, Orduñez P, et al. Population-wide weight loss and regain in relation to diabetes burden and cardiovascular mortality in Cuba 1980-2010: repeated cross sectional surveys and ecological comparison of secular trends. BMJ 2013;346:f1515.

44. Wing RR, Phelan S. Long-term weight loss maintenance. Am J Clin Nutr 2005;82(1 Suppl):222S-5.

45. Marfell-Jones M, Olds T, Stewart A, et al. International Standards for Anthropometric Assessment. Potchefstroom, RSA: North-West University, 2006.

46. World Health Organization. Physical status: the use of and interpretation of anthropometry. Geneva, Switzerland: World Health Organization, 1995.

47. Kuczmarski RJ, Ogden CL, Grummer-Strawn LM, et al. CDC growth charts: United States. Adv Data 2000;314:1-27.

48. Cole TJ, Freeman JV, Preece MA. British 1990 growth reference centiles for weight, height, body mass index and head circumference fitted by maximum penalized likelihood. Stat Med 1998;17:407-29.

49. Cole TJ, Flegal KM, Nicholls D, et al. Body mass index cut offs to define thinness in children and adolescents: international survey. BMJ 2007;335:194.

50. World Health Organization. Global Database on Body Mass Index. 2017 http://apps.who.int/bmi/index.jsp?introPage=intro_3.html.

51. McCarthy HD, Cole TJ, Fry T, et al. Body fat reference curves for children. Int J Obes 2006;30:598-602.

52. Petersen AC, Crockett L, Richards M, et al. A self-report measure of pubertal status: reliability, validity, and initial norms. J Youth Adolesc 1988:17:117-33.

53. Australian Bureau of Statistics. Census of Population and Housing: Socio-Economic Indexes for Areas (SEIFA). Cat. no. 2033.0.55.001 Australia 2011. 2013 http://www.abs.gov.au/websitedbs/ censushome.nsf/home/seifa2011. 